\title{
Pengaruh Selubung Bangunan Terhadap Kenyamanan Termal (Studi Kasus PPSDM Migas Cepu)
}

\author{
Aspita Dyah Fajarsari* \\ PPSDM Kelistrikan, Energi Baru Terbarukan dan Konservasi Energi, Jakarta
}

\begin{abstract}
ABSTRAK
Pusat Pengembangan Sumber Daya Manusia Minyak dan Gas Bumi (PPSDM Migas) Cepu merupakan satuan kerja Badan Pengembangan Sumber Daya Manusia Energi dan Sumber Daya Mineral (BPSDM ESDM). Dengan pentingnya fungsi dari bangunan ini, maka dibutuhkan pemenuhan aspek kenyamanan termal untuk menunjang aktifitas di dalamnya. Kajian ini bertujuan untuk memahami bagaimana pengaruh penerapan material selubung bangunan terhadap kenyamanan termal dalam bangunan. Kenyamanan termal dipengaruhi oleh kualitas kenyamanan termal, pemilihan jenis dan warna material selubung bangunan serta luas material transparan.

Metode penelitian yang digunakan adalah metode penelitian kualitatif, kuantitatif dan kualitatif yang dikuantitatifkan. Kajian ini diharapkan dapat menjadi rujukan saat mendesain sebuah bangunan kantor yang dapat menunjang kenyamanan termal di dalam bangunan.
\end{abstract}

Kata kunci: selubung bangunan, kenyamanan termal, gedung kantor

\begin{abstract}
This document provides instructions on the paper writing format to be published in Swara Patra. The author is required to follow the instructions in this document so that the paper can be published. The author may view this document as an instruction as well as a template by replacing the text in it according to the prepared paper. Documents are written in Indonesian using enhanced spellings.

Human Resources Development Center for Oil and Gas is one of unit Human Resources Development Agency for Energy and Mineral Resources. With the most important function of this building, thermal comfort is necessary for supporting an activities in it. This research purposed to know how the building envelope material influenced thermal in buldings. Thermal comfort influenced by thermal comfort quality, kind of colour material building envelope selection, and transparant material.
\end{abstract}

Keywords: (building envelope, thermal comfort, office building)

email: aspita.d.fajarsari@esdm.go.id 


\section{PENDAHULUAN}

Salah satu isu yang sekarang menjadi perhatian seluruh masyarakat adalah isu pemanasan global (global worming). Akibat yang ditimbulkan dari pemanasan global ini bahkan sudah dirasakan oleh seluruh penduduk di dunia. Iklim yang berubah secara cepat, jumlah es di kutub yang sudah banyak mencair, kenaikan muka air laut, banjir, kebakaran hutan merupakan sedikit contoh kejadian dari sekian banyak yang memberikan pertanda terjadinya pemanasan global.

Penyumbang terbesar yang menyebabkan terjadinya pemanasan global ini adalah sektor bangunan gedung di mana sekitar $40 \%$ penggunaan energi dan emisi gas rumah kaca dihasilkan. Namun demikian sektor bangunan gedung ini juga memiliki potensi yang besar untuk dapat mengurangi emisi gas rumah kaca yang mempengaruhi pemanasan global.

Bangunan gedung merupakan bagian dari lingkungan yang bertujuan menciptakan ruang yang nyaman untuk penghuni dan/atau pengguna bangunan gedung tersebut. Untuk itu perlu diupayakan suatu teknologi hemat energi pada bangunan gedung untuk meminimalkan penggunaan energi. Hemat energi yang dimaksud tentunya tanpa mengurangi kenyamanan penghuni. Dengan kemajuan teknologi dimana cara berfikir manusia yang semakin maju dan mampu menjadikan konsep bangunan yang baik untuk manusia dan lingkungan.

Badan Pengembangan Sumber Daya Manusia Energi dan Sumber Daya Mineral (BPSDM ESDM) sebagai salah satu Instansi Pemerintah yang memiliki banyak Satuan Kerja yang tersebar maka bangunan gedung menjadi perhatian. Penelitian kali ini dilakukan di Pusat Pengembangan Sumber Daya Manusia Minyak dan Gas Bumi (PPSDM Migas) di Cepu, Blora, Jawa Tengah.

PPSDM Migas sebagai salah satu contoh bangunan pada umumnya yang nantinya akan dilihat apakah sudah diterapkan pembangunan berkelanjutan. Tujuan dilakukannya penelitian ini adalah untuk mengetahui dan memahami pengaruh penerapan material pada selubung bangunan yang mempengaruhi kenyamanan termal di dalam bangunan.

Permasalahan yang dibahas dalam kajian ini meliputi; bagaimana konsep perancangan desain selubung bangunan, bagaimana dampak dalam pemilihan jenis material selubung bangunan ditinjau dari kenyamanan termal di dalam bangunan.

\section{TINJAUAN PUSTAKA}

Selubung bangunan adalah elemen bangunan yang membungkus bangunan gedung, yaitu dinding dan atap transparan atau yang tidak transparan dimana sebagian besar energi termal berpindah melewati elemen tersebut. Penggunaan material selubung bangunan tentunya akan sangat berpengaruh terhadap kenyamanan termal pada ruangan yang ada pada bangunan tersebut. Hal ini akan dibahas secara lengkap berikut ini.

\section{A. Material Selubung Bangunan}

\section{A.1. Kaca}

Kaca adalah elemen penting pada bangunan, baik rumah tinggal, pertokoan, gedung bertingkat tinggi, dll. Fungsi kaca adalah untuk pecahayaan alami, selain itu juga sebagai bagian dari estetika bangunan.

Jenis kaca yang dapat digunakan untuk bangunan maupun rumah tinggal antara lain kaca bening, kaca warna, kaca es, kaca reflektif, kaca tempered, kaca laminated, dll. Contoh penampakan kaca dapat dilihat pada gambar berikut ini.

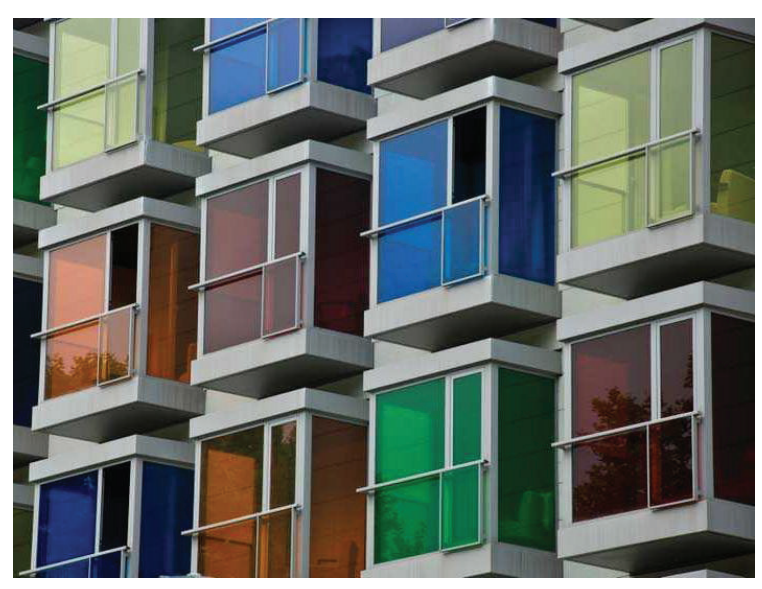

Gambar 1. Tinted glass

(Sumber: www.romag.co.uk) 


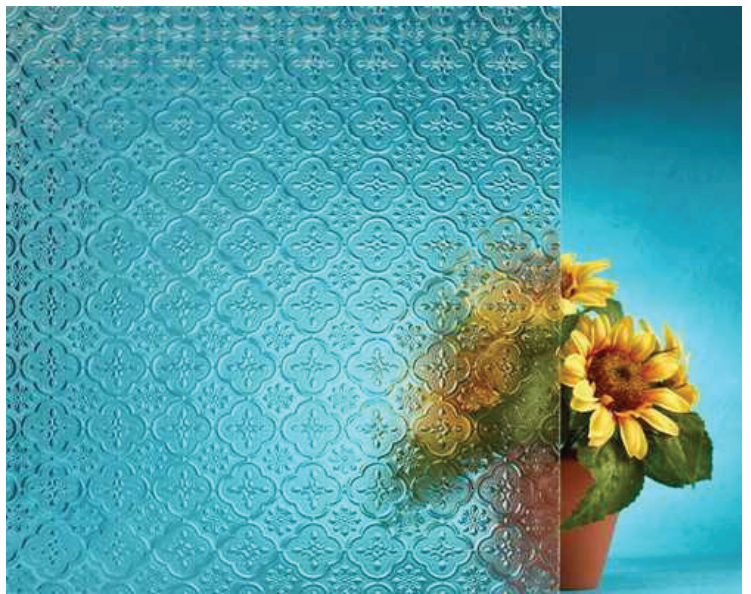

Gambar 2. Kaca es

(Sumber: www.archipidi.net)

Terdapat beberapa jenis kaca yang digunakan dalam bangunan gedung. Jenis kaca yang digunakan di PPSDM Migas Cepu adalah kaca bening.

\section{A.2. Beton}

Beton merupakan material yang dapat menghambat perpindahan panas masuk ke dalam bangunan. Dalam konstruksi, beton memiliki keunggulan yaitu dapat dicetak sesuai keinginan dan tahan lama.

\section{A.3. Aluminium Composite Panel (ACP)}

Alumunium Composite Panel (ACP) adalah bahan perpaduan antara plat alumunium dan bahan composite. ACP digambarkan sebagai plat datar yang terdiri dari bahan non-alumunium berupa bahan polyethylene yang disatukan di antara dua lembaran alumunium. Lembaran ACP berupa lembaran yang kaku, kuat, tetapi beratnya relatif ringan. Material ini juga sering dikenal dengan sandwich panel (panel sandwich).

Dalam pemakaiannya, ACP banyak digunakan sebagai pelapis permukaan dinding dinding eksterior untuk memberi kesan artistik pada fasad bangunan. Bahan ini biasanya digunakan untuk bangunan gedung seperti pertokoan, ruko, hotel, dll. Material ini sering juga dikombinasikan dengan kaca dan bahan logam lainnya untuk keindahan arsitektur. ACP juga bisa digunakan untuk interior seperti untuk partisi, penutup kolom, dan juga untuk plafon artistik. Selain kegunaan di atas, ACP juga berfungsi untuk memfilter radiasi matahari yang masuk ke bangunan.

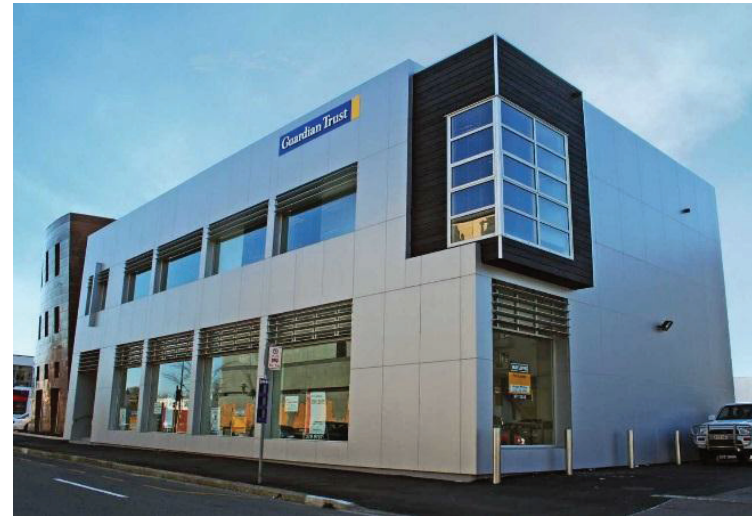

Gambar 3. ACP pada fasad bangunan (Sumber: royaltouchinteriors.in)

Menurut lapisan catnya, ACP terdiri dari 2 (dua) jenis, yaitu :

1) Jenis Polyester (PE), yang biasa digunakan untuk interior.

2) Jenis Poly Vinyl De Flouride (PVDF), yang biasa digunakan untuk eksterior.

Beberapa karakterisitik ACP yang membuat material ini menjadi pilihan di bidang konstruksi adalah :

- Tahan panas

ACP memiliki nilai-U yang berbeda-beda tergantung pada jenis material, inti dan ketebalan panel. Pemasangan sistem dengan panel sandwich meminimalkan jembatan termal melalui sambungan.

- Isolasi akustik

ACP juga dapat berperan sebagai isolator untuk reduksi suara yang terletak pada kisaran 25 $\mathrm{dB}-30 \mathrm{~dB}$ tergantung jenis masterial yang digunakan.

\section{- Sifat mekanis}

a. Jarak antara penopang bisa sampai $11 \mathrm{~m}$ (dinding), tergantung pada jenis panel yang digunakan. Pada aplikasi normal jarak antara penopang sekitar $3 \mathrm{~m}-5 \mathrm{~m}$.

b. Ketebalan panel adalah $40 \mathrm{~mm}$ hingga lebih dari $200 \mathrm{~mm}$.

c. Kepadatan panel sandwich berkisar dari 10 $\mathrm{kg} / \mathrm{m} 2$ hingga $35 \mathrm{~kg} / \mathrm{m} 2$, tergantung pada busa dan ketebalan logam. Hal ini berperan 
dalam mempersingkat waktu yang diperlukan untuk transportasi, penanganan dan pemasangan panel.

d.Semua sifat geometris dan material ini mempengaruhi perilaku kegagalan global/lokal ACP di bawah kondisi pembebanan yang berbeda seperti indentasi, benturan, dan melengkung.

- Sifat tahan api

a. ACP memiliki perilaku resistansi dan reaksi terhadap api yang berbeda, tergantung pada: busa, ketebalan logam, lapisan, dll. Pengguna harus memilih antara jenis panel sandwich yang berbeda, sesuai kebutuhan.

b.Penelitian oleh Association of British Insurers (Asosiasi Penjamin Asuransi Inggris) dan Building Research Establishment (Lembaga Penelitian Bangunan) di Inggris menyoroti bahwa ACP tidak mengakibatkan kebakaran, meskipun telah terlibat dalam penyebaran api. Api sering kali dimulai di daerah berisiko tinggi seperti sebagai area memasak, kemudian menyebar sebagai akibat dari manajemen risiko kebakaran, pencegahan, dan sistem pengaman api yang buruk.

c. Ada bukti bahwa ketika ACP digunakan untuk memadatkan bangunan, panel ini dapat berkontribusi pada penyebaran api yang cepat di luar gedung.

d.Adanya rongga antara kelongsong dan dinding luar bangunan (atau sarung insulasi) juga signifikan: api dapat menempati rongga dan ditarik ke atas oleh konveksi yang mengakibatkan kebakaran sekunder, terlepas materi apa yang digunakan untuk melapisi rongga.

- Impermeabilitas (kemampuan kedap air) Sistem perakitan ACP membantu menciptakan bangunan menjadi kedap udara dan kedap air.

\section{A.4. Genteng}

Atap juga merupakan selubung bangunan. Salah satu komponennya adalah genteng. Banyak jenis genteng yang dipakai saat ini tergantung dari jenis bahannya seperti tanah liat, kayu, batu, serat, aspal, plastik, asbes, dan logam tergantung kebutuhan dan biaya pembangunan.

\section{B. Dampak dalam Pemilihan Jenis Material Selubung Bangunan terhadap Kenyamanan Termal di Dalam Bangunan}

\section{B.1. Kualitas Kenyamana Termal}

Kenyamanan dan perasaan nyaman adalah penilaian subyektif seseorang terhadap lingkungannya. Oleh karena itu kenyamanan tidak dapat diwakili oleh suatu angka. Kita menilai kondisi lingkungan berdasarkan rangsangan yang masuk ke diri kita melalui indera kita yang oleh syaraf dibawa ke otak dan dinilai. Kekurangan (ketidaknyamanan) di satu faktor dapat ditutupi oleh faktor lain.

Beberapa faktor yang dikaitkan dengan kenyamanan tertentu, misalnya:

- Ras, sebenarnya tidak ditemukan bukti bahwa ras mempengaruhi penilaian akan kenyamanan. Manusia mempunyai kemampuan adaptasi terhadap iklim (aklimatisasi) dengan baik. Normalnya orang dapat menyesuaikan diri dalam waktu 2 minggu.

- Jenis kelamin, perempuan umumnya menyukai lingkungan yang $1^{\circ} \mathrm{C}$ lebih hangat daripada laki-laki.

- Usia, orang berusia lanjut lebih suka di lingkungan yang lebih hangat dan tidak berangin. Hal ini karena kemampuan metabolisme tubuh orang berusia lanjut cenderung menurun.

Georg Lippsmeier menjelaskan faktor yang mempengaruhi kenyamanan termal di suatu banguna terbagi menjadi 2, yaitu faktor eksternal dan internal.

a) Faktor Eksternal

- Suhu Udara

Suhu udara cukup mudah diukur dengan termometer ruangan. Memperkirakan suhu udara yang cukup nyaman cukup sulit karena kemampuan adaptasi setiap orang berbedabeda.

Kondisi udara ruang yang direncanakan harus sesuai dengan fungsi dan persyaratan penggunaan ruangan yang dimuat dalam standar. Pada SNI 6390:2011 tentang Konservasi 
Energi Sistem Tata Udara Bangunan Gedung pada bab Perhitungan Teknis dinyatakan:

1) Untuk memenuhi kenyamanan termal pengguna banguan, kondisi perencanaan gedung yang berada di wilayah rendah (atau pantai) dengan suhu udara maksimum rata-rata sekitar $34^{\circ} \mathrm{C}$ DB dan $28^{\circ} \mathrm{C}$ WB (atau suhu rata-rata bulanan sekitar $28^{\circ} \mathrm{C}$ ) ditetapkan bahwa:

- Ruang kerja: temperatur bola kering berkisar antara $24^{\circ} \mathrm{C}$ hingga $27^{\circ} \mathrm{C}$ atau $25,5^{\circ} \mathrm{C} \pm 1,5^{\circ} \mathrm{C}$, dengan kelembapan relatif $60 \% \pm 5 \%$.

- Ruang transit (lobi, koridor): temperatur bola kering berkisar antara $27^{\circ} \mathrm{C}$ hingga $30^{\circ} \mathrm{C}$ atau $28,5^{\circ} \mathrm{C} \pm 1,5^{\circ} \mathrm{C}$, dengan kelembapan relatif $60 \% \pm 10 \%$.

2) Untuk wilayah tinggi atau pegunungan, dengan suhu udara maksimum rata-rata sekitar $28^{\circ} \mathrm{C}$ DB dan $24^{\circ} \mathrm{C}$ WB (atau suhu rata-rata bulanan sekitar $23^{\circ} \mathrm{C}$ atau kurang).

- Kelembapan Udara

Kelembapan relatif udara (RH) dapat diukur dengan hygrometer. Alat tersebut cukup mudah di dapat dan murah, biasanya menjadi satu bagian dengan termometer dan namanya menjadi thermo-hygrometer. Referensi kelembapan udara dapat menggunakan SNI 6390:2011 tentang Konservasi Energi Sistem Tata Udara Bangunan Gedung.

- Kecepatan Angin

Lippsmeier menyatakan bahwa patokan untuk mencari kecepatan angin adalah:

- $0,25 \mathrm{~m} / \mathrm{s}$ adalah nyaman, tanpa dirasakan adanya gerakan udara.

- $0,25-0,5 \mathrm{~m} / \mathrm{s}$ adalah nyaman, gerakan udara terasa.

- $1,0-1,5 \mathrm{~m} / \mathrm{s}$ aliran udara ringan sampai tidak menyenangkan.

b) Faktor Internal

- Di atas $1,5 \mathrm{~m} / \mathrm{s}$ tidak menyenangkan.

Faktor internal dibagi menjadi 5 (lima) variabel, yaitu kondisi perancangan, penetapan sistem dan peralatan tata udara, sistem pengkondisian sentral, tingkat pekerjaan, serta pakaian. Dari kelima variabel di atas, hanya sistem pengkondisian udara saja yang tidak termasuk variabel yang diabaikan.

\section{B.2. Pengaruh Pemilihan Jenis dan Warna Material Selubung Bangunan}

Selubung bangunan yang menggunakan material dengan nilai hambatan hantaran panas yang cukup besar dan mempunyai kemampuan untuk memantulkan panas yang cukup baik akan sangat membantu mengurangi penggunaan alat pendingin ruangan (AC) di siang hari. Warna cerah seperti putih memiliki nilai serapan kalor yang lebih sedikit yaitu berkisar antara 10\% - 15\% sedangkan pada warna tua seperti hitam dapat menyerap kalor sampai 95\%.

\section{B.3. Luas Material Transparan}

Nilai ideal bukaan bangunan adalah $20 \%$ dari luas dinding keseluruhan. Sinar matahari dengan kuat penerangan mencapai 10.000 lux atau lebih dapat menyebabkan silau, maka dari itu jendela tersebut harus diberi sarana pencegah kesialauan.

\section{METODE PENELITIAN}

Metode penelitian yang digunakan dalam kajian ini adalah metode penelitian kualitatif, kuantitatif, dan kualitatif yang dikuantitatifkan. Adapun pengukuran suhu dan kelembapan udara dengan menggunakan alat ukur suhu dan kelembapan yaitu Humidity/Temperature Meter dan alat pengukur kecepatan angin yaitu Anemometer. Namun karena keterbatasan alat ukur, pada kasus pengukuran indeks kesilauan akan diukur secara kualitatif sehingga tidak memunculkan angka pasti hanya berupa pendapat dari observer (pengamat). Proses pengukuran dilakukan dalam waktu 4 (empat) hari yaitu Senin (28 Mei 2018), Rabu (30 Mei 2018), Kamis (31 Mei 2018) dan Jumat (1 Juni 2018). Dalam satu hari dilakukan 2 sesi pengukuran yaitu sesi pertama pada pukul 08.00 - 09.00 WIB dan sesi kedua pada pukul 13.00 - 14.00 WIB. Pengukuran hanya dilakukan di lobi dan lorong lantai 1 bagian timur dan barat. 
HASIL PENELITIAN DAN PEMBAHASAN

\section{A. Analisis Material Selubung Bangunan}

Selubung bangunan yang diunkan pada PPSDM Migas Cepu, pada bangian dinding menggunakan kaca bening dan ACP. Sedangkan untuk genting menggunakan genting tanah dan genting keramik.

Luas selubung bangunan untuk dinding \pm $1.841,58 \mathrm{~m} 2$ yang terdiri dari luas bagian kaca \pm $791,88 \mathrm{~m} 2$ dan luas ACP 1.049,70 m2. Sedangkan selubung bangunan untuk atap $\pm 1.788,43 \mathrm{~m} 2$ dengan atap skylight $\pm 135 \mathrm{~m} 2$.

\section{A.1. Analisis Jenis Pemilihan Material}

\section{A.1.1. Kaca}

Penggunaan kaca pada fasad bangunan menjadi alternatif untuk mendesain bangunan. Pemilihan ini bertujuan untuk memenuhi kebutuhan pandangan ke arah keluar. Pada gedung PPSDM Migas Cepu, material kaca digunakan pada selubung bangunan. Material kaca dipasang pada dinding di setiap lantainya serta juga dipasang sebagai skylight di area lobi, sehingga juga bermanfaat untuk pencahayaan alami pada gedung.

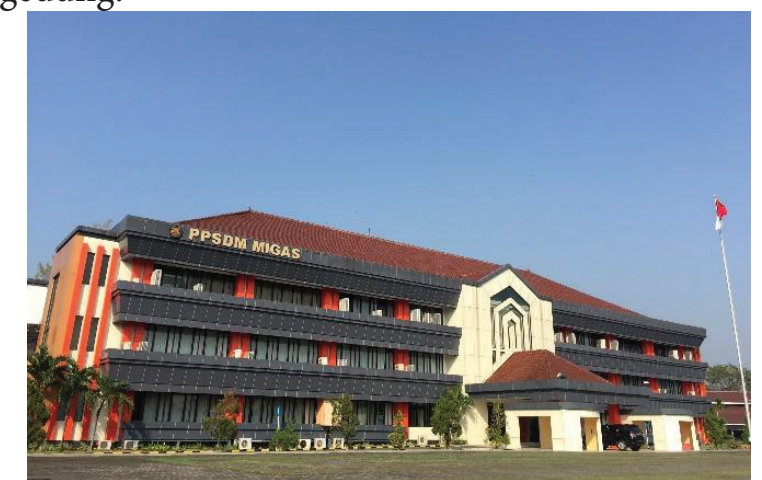

Gambar 4. Selubung Bangunan Gedung PPSDM Migas Cepu

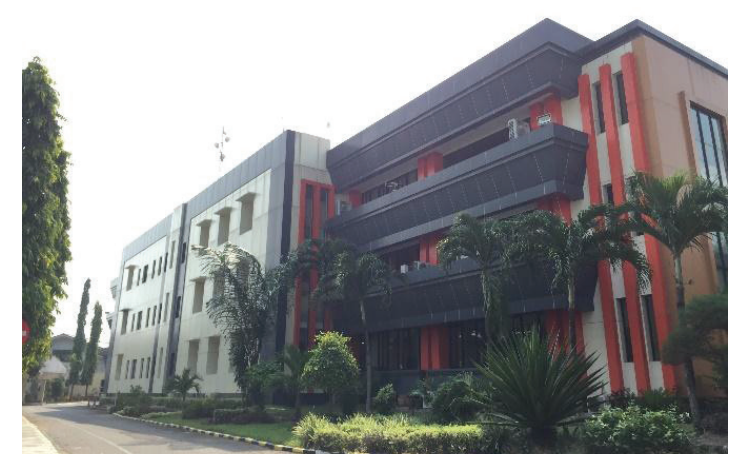

Gambar 5. Selubung Bangunan Gedung PPSDM Migas Cepu (Tampak Belakang)
Jenis kaca yang digunakan adalah kaca bening. Memang pada kaca bening memiliki nilai Solar Factor (SF) yang tinggi yaitu sebesar $83 \%$. Namun demikian nilai transmittance kaca bening/clear floating glass tinggi yaitu sebesar $89 \%$ sehingga perolehan cahaya alami yang masuk ke dalam bangunan akan tinggi.

\section{A.1.2. Beton}

Beton merupakan material yang memiliki kemampuan menghambat perpindahan panas masuk ke dalam bangunan. Beton memiliki keunggulan yaitu dapat dicetak sesuai kebutuhan dengan hasil akhir menyatu secara solid dan tahan lama.

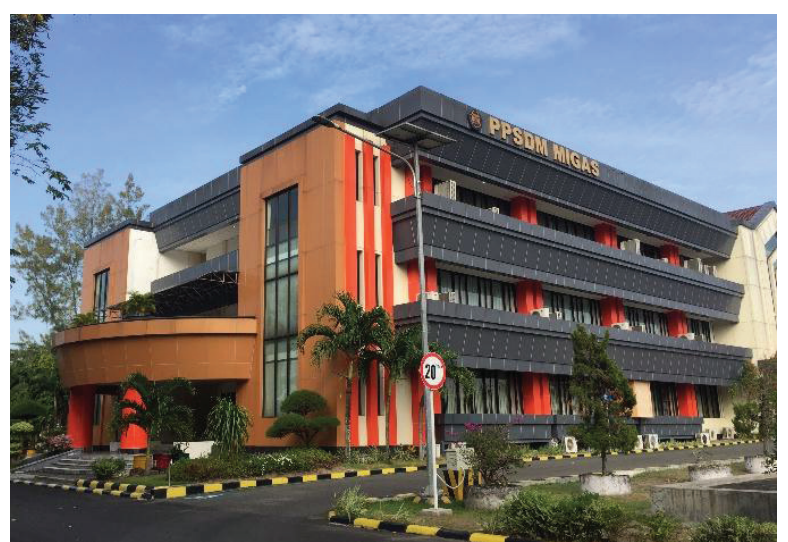

Gambar 6. Selubung Bangunan Gedung PPSDM Migas Cepu (Tampak Samping Kiri)

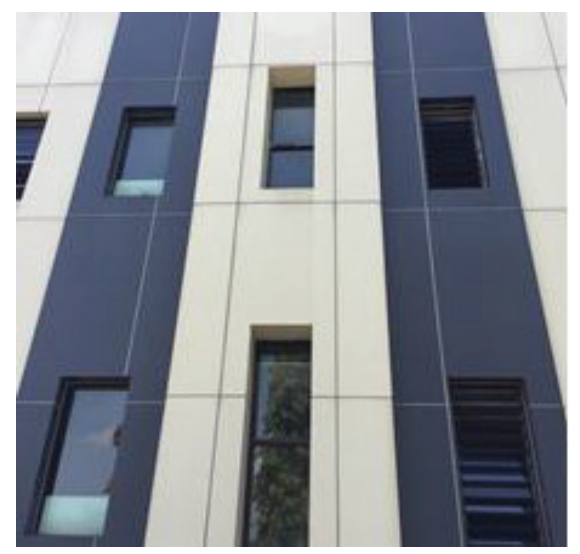

Gambar 7. Selubung Bangunan Gedung PPSDM Migas Cepu (Tampak Belakang) 
Pada PPSDM KEBTKE, bagian dinding bangunan terbuat dari beton, namun dilapisi lagi dengan menggunakan bahan Aluminium Composite Panel (ACP), sehingga bagian terluar yang akan dipertimbangkan dalam kenyamanan termal adalah ACP.

\section{A.1.3. Aluminium Composite Panel (ACP)}

Selain material kaca, selubunga bangunan pada gedung PPSDM Migas Cepu juga menggunakan ACP. Seperti yang tampak pada gambar 4, 5, 6 dan 7. ACP berfungsi untuk memfilter radiasi matahari sehingga dapat mengurangi panas yang masuk ke dalam bangunan.

Sesuai dengan Tabel 1, nilai absorbtans radiasi matahari untuk dinding luar dan atap tidak transparan pada SNI 6389:2011 tentang Konservasi Energi selubung bangunan pada bangunan gedung, memperlihatkan bahwa nilai penyerapan untuk material aluminium mempunyai nilai yang rendah. Artinya bahwa material aluminium ini cukup efektif untuk mengurangi panas pada bangunan.

Tabel 1. Nilai absortans radiasi matahari untuk dinding luar dan atap tidak transparan

\begin{tabular}{|l|c|}
\hline \multicolumn{1}{|c|}{ Bahan dinding luar } & $\alpha$ \\
\hline Beton berat ${ }^{1)}$ & 0,91 \\
\hline Bata merah & 0,89 \\
\hline Bituminous felt & 0,88 \\
\hline Batu sabak & 0,87 \\
\hline Beton ringan & 0,86 \\
\hline Aspal jalan setapak & 0,82 \\
\hline Kayu permukaan halus & 0,78 \\
\hline Beton ekspos & 0,61 \\
\hline Ubin putih & 0,58 \\
\hline Bata kuning tua & 0,56 \\
\hline Atap putih & 0,50 \\
\hline Cat alumunium & 0,40 \\
\hline Kerikil & 0,29 \\
\hline Seng putih & 0,26 \\
\hline Bata glazur putih & 0,25 \\
\hline Lembaran alumunium yang dikilapkan & 0,12 \\
\hline
\end{tabular}

Untuk bangunan nuklir

Sumber: SNI 6389:2011 Konservasi Energi Selubung Bangunan pada Bangunan Gedung

\section{A.1.4. Peneduh}

Peneduh secara tidak langsung juga menjadi faktor yang mempengaruhi kenyamanan termal. Pada gedung PPSDM Migas cepu banyak pohon yang tumbuh disekitarnya. Pohon sebagai peneduh ini berfungsi sebagai filter radiasi matahari sehingga suhu disekitarnya cenderung menurun dengan mengurangi pelepasan panas.

\section{A.1.5. Genteng}

Genteng yang digunakan adalah genteng keramik dan genteng kaca. Genteng keramik terbuat dari bahan yang sama dengan genteng tradisional, yaitu tanah liat.

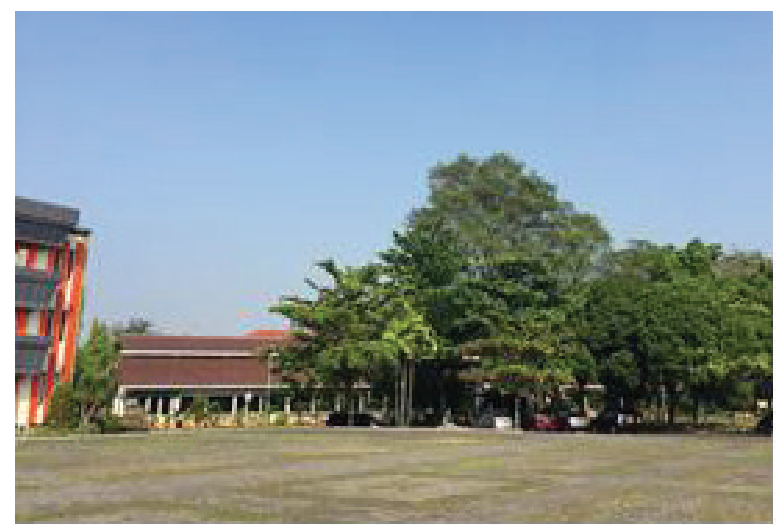

Gambar 8. Lingkungan sekitar Gedung PPSDM Migas

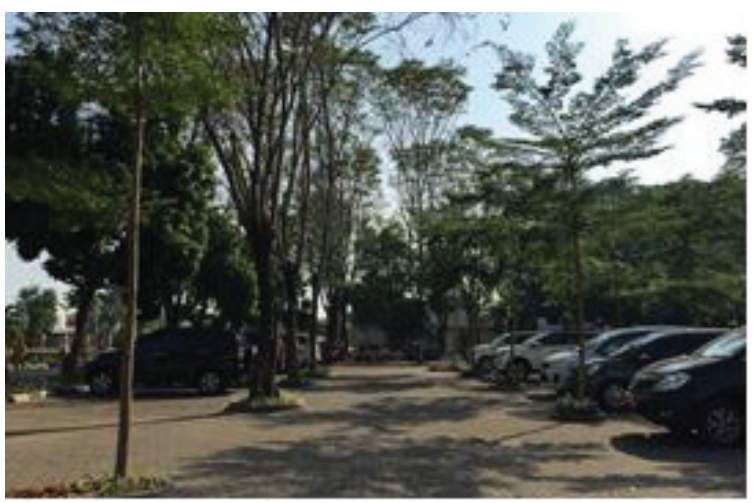

Gambar 9. Lingkungan sekitar Gedung PPSDM Migas

Namun pada saat proses pembuatan genteng keramik, material tanah liat disortir, lalu dicetak dan dipress menggunakan peralatan modern sehingga kekuatan, kepresisian dan kerapihannya sangat baik sehingga menyerupai keramik lantai. Sedangkan genteng kaca digunakan untuk 
memasukkan cahaya matahari ke dalam bangunan.

\section{A.1.6. Peneduh}

Peranan peneduh dalam mengurangi panas pada bangunan gedung sangat besar. Salah satu peneduh yang mudah ditemui adalah pepohonan.

Dengan adanya pepohonan ini, udara panas yang masuk ke dalam bangunan dapat dihalau sehingga hawa ruangan dapat tetap sejuk. Idealnya, perbandingan antara bangunan dan area hijau adalah 60:40.

Namun, ini diimplementasikan karena sulit untuk keadaan sekarang dimana lahan yang semakin sempit. Hal inilah yang mengakibatkan udara panas masuk ke rongga ruangan dan udara panas akan dirasakan penghuni.

Di PPSDM Migas Cepu banyak terdapat area hijau di sekitar bangunan. Ini merupakan contoh implementasi peneduh yang juga berfungsi untuk mengurangi udara panas yang masuk ke bangunan.

\section{B. Analisis Dampak dalam Pemilihan Jenis Material Selubung Bangunan terhadap Kenyamanan Termal di Dalam Bangunan B.1. Analisis Faktor Kualitas Kenyamanan Termal}

\section{B.1.1. Analisis Faktor Eksternal}

Hasil analisis menunjukkan faktor eksternal pada ruang dalam gedung kantor PPSDM Migas Cepu ini adalah cukup baik dalam mendukung terwujudnya kenyamanan termal. Berikut hasil analisis yang dilakukan:

a) Suhu udara

Hasil pengukuran yang dilakukan di Gedung PPSDM Migas Cepu antara lain pengukuran suhu udara, kelembapan relatif dan kecepatan angin dapat dilihat pada Tabel 2. Dari hasil pengukuran suhu udara rata-rata berkisar antara $26,5-33,8^{\circ} \mathrm{C}$. Hal ini memperlihatkan bahwa suhu di lingkungan PPSDM Migas Cepu cukup tinggi.

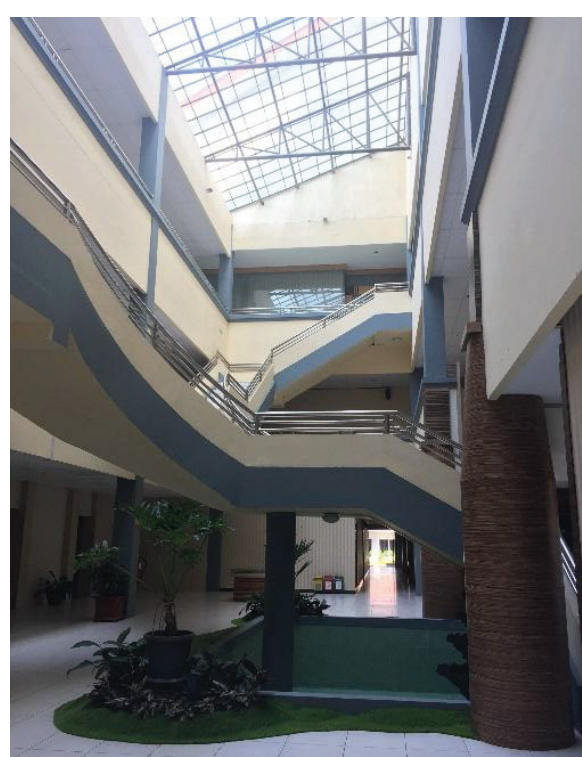

Gambar 10. Lobi Gedung PPSDM Migas Cepu

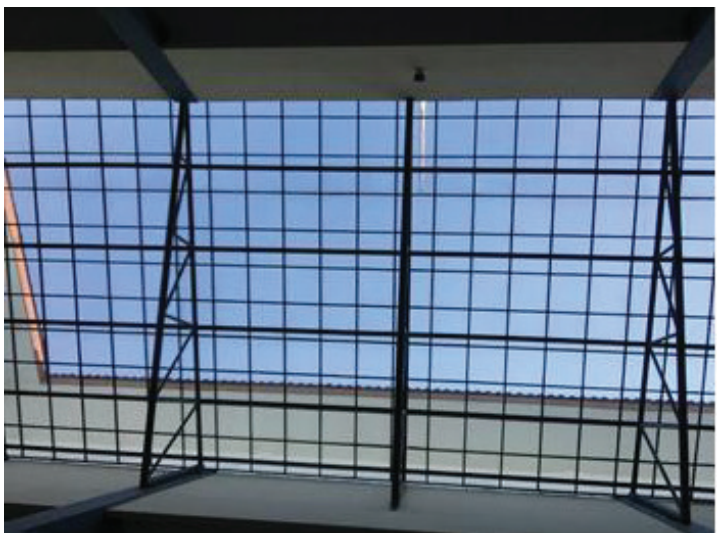

Gambar 11. Atas Skylight

b) Kelembapan udara

Berdasarkan Tabel 2 di atas, dapat dilihat bahwa nilai rata-rata kelembapan udara pada gedung kantor PPSDM Migas Cepu berkisar antara $43-70 \%$. Hasil analisis ini menunjukkan bahwa kelembapan udara cukup baik untuk digunakan beraktifitas.

c) Kecepatan angin

Dari hasil analisis dengan dikorelasikan teori Lippsmeimer, angin yang berhembus ke dalam bangunan adalah beragam. Ada lokasi-lokasi yang terdapat gerakan udara. Pengaruh gerakan udara yang merupakan penghawaan alami dapat dirasakan di lantai 
1, karena di lantai 1 terdapat 3 bukaan alami yaitu main lobi, lorong kanan dan lorong kiri.

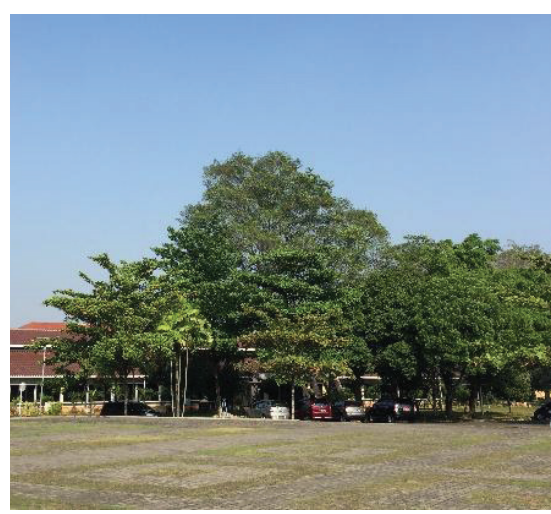

Gambar 12. Halaman Depan Gedung Kantor PPSDM Migas Cepu

\section{B.1.2. Analisis Faktor Internal}

Kajian mengenai analisis faktor internal hanya meliputi sistem pengkondisian udara. Hasil analisis menunjukkan faktor internal pada gedung PPSDM Migas Cepu adalah baik dalam mendukung kenyamanan termal. Berikut analisis yang dilakukan.

Kenyamanan termal pada bangunan PPSDM Migas Cepu ditinjau dari besaran suhu yang dihasilkan oleh penghawaan buatan sistem pengkondisian udara adalah baik yaitu berkisar pada $24^{\circ} \mathrm{C}-27^{\circ} \mathrm{C}$. Hal ini sesuai dengan persyaratan pada SNI.

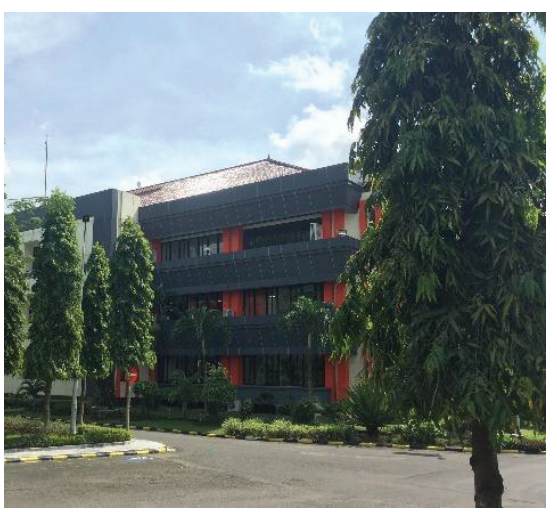

Gambar 13. Halaman Belakang Gedung Kantor PPSDM Migas Cepu

\section{B.2. Analisis Pengaruh Pemilihan Jenis dan Warna Material Selubung Bangunan}

Hasil analisis menunjukkan pengaruh pemilihan jenis dan warna material selubung bangunan adalah baik dalam mendukung terwujudnya kenyamanan termal. Berikut hasil analisis yang dilakukan:

Tabel 2. Hasil pengukuran Suhu Udara,

Kelembapan Udara dan Kecepatan Angin

\begin{tabular}{|c|c|c|c|c|c|}
\hline Tanggal & $\begin{array}{c}\text { Lokasi } \\
\text { (Pintu Masuk) }\end{array}$ & Jam & $\mathrm{T}\left({ }^{\circ} \mathrm{C}\right)$ & $\begin{array}{l}\mathrm{RH} \\
(\%)\end{array}$ & $\begin{array}{c}\text { Vel } \\
(\mathrm{m} / \mathrm{s})\end{array}$ \\
\hline \multirow[t]{7}{*}{ 28-May } & Lorong Kanan & 08.36 & 28,3 & 65,60 & 0,55 \\
\hline & Lobi Utama & 08.39 & 28,5 & 66,63 & 0,00 \\
\hline & Lorong Kiri & 08.41 & 27,7 & 66,00 & 0,00 \\
\hline & Ruang Humas & 08.48 & 27,8 & 57,71 & 0,01 \\
\hline & Lorong Kiri & 13.27 & 31,9 & 53,14 & 0,00 \\
\hline & Lobi Utama & 13.30 & 32,0 & 53,15 & 1,58 \\
\hline & Lorong Kanan & 13.51 & 29,1 & 60,35 & 0,59 \\
\hline \multirow[t]{6}{*}{ 30-May } & Lorong Kanan & 08.21 & 28,2 & 66,25 & 0,00 \\
\hline & Lobi Utama & 08.27 & 28,1 & 67,17 & 0,00 \\
\hline & Lorong Kiri & 08.33 & 26,5 & 71,76 & 1,23 \\
\hline & Lorong Kiri & 13.54 & 30,5 & 57,79 & 0,01 \\
\hline & Lobi Utama & 13.57 & 31,2 & 59,23 & 0,65 \\
\hline & Lorong Kanan & 14.03 & 31,7 & 56,08 & 1,50 \\
\hline \multirow[t]{6}{*}{$\begin{array}{c}\text { 31-May- } \\
18\end{array}$} & Lorong Kanan & 08.38 & 27,2 & 67,64 & 0,02 \\
\hline & Lobi Utama & 08.44 & 28,2 & 67,90 & 0,00 \\
\hline & Lorong Kiri & 08.56 & 27,6 & 67,71 & 0,00 \\
\hline & Lobi Utama & 12.38 & 31,8 & 51,86 & 0,00 \\
\hline & Lorong Kanan & 12.46 & 31,9 & 49,90 & 0,00 \\
\hline & Lorong Kiri & 12.53 & 32,1 & 53,14 & 0,01 \\
\hline \multirow{6}{*}{$\begin{array}{c}1 \text {-Jun- } \\
18\end{array}$} & Lorong Kiri & 09.52 & 29,2 & 56,79 & 0,68 \\
\hline & Lobi Utama & 09.58 & 31,0 & 53,59 & 0,04 \\
\hline & Lorong Kanan & 10.06 & 30,3 & 55,96 & 1,44 \\
\hline & Lorong Kiri & 11.58 & 31,7 & 48,26 & 0,04 \\
\hline & Lobi Utama & 12.03 & 33,8 & 43,02 & 1,16 \\
\hline & Lorong Kanan & 12.05 & 32,6 & 43,90 & 0,95 \\
\hline
\end{tabular}


Pengaruh Pemilihan Jenis Material Selubung Bangunan

Terdapat 3 (tiga) jenis material yang digunakan sebagai penutup selubung bangunan yang dikaji yaitu kaca, ACP dan genteng keramik.

a) Pengaruh Pemilihan Warna Material Selubung Bangunan

Penggunaan ACP berwarna krem dan coklat yang mempunyai angka serapan kalor yang rendah sehingga menjadikan ACP cukup baik sebagai material thermal mass. Secara keseluruhan pengaruh warna material selubung bangunan pada kenyamanan termal cukup baik, hal ini juga dibantu dengan sistem penghawaan alami dan buatan di dalam bangunan sehingga membuat suhu ruang dalam menjadi nyaman.

Tabel 3. Nilai Absortans radiasi matahari untuk cat permukaan dinding luar

\begin{tabular}{|l|c|}
\hline \multicolumn{1}{|c|}{ Cat permukaan dinding luar } & $\alpha$ \\
\hline Hitam merata & 0,95 \\
\hline Pernis hitam & 0,92 \\
\hline Abu-abu tua & 0,91 \\
\hline Pernis biru tua & 0,91 \\
\hline Cat minyak hitam & 0,90 \\
\hline Coklat tua & 0,88 \\
\hline Abu-abu/biru tua & 0,88 \\
\hline Biru/hijau tua & 0,88 \\
\hline Coklat medium & 0,84 \\
\hline Pernis hijau & 0,79 \\
\hline Hijau medium & 0,59 \\
\hline Kuning medium & 0,58 \\
\hline Hijau/biru medium & 0,57 \\
\hline Hijau muda & 0,47 \\
\hline Putih semi kilap & 0,30 \\
\hline Putih kilap & 0,25 \\
\hline Perak & 0,25 \\
\hline Pernis putih & 0,21 \\
\hline
\end{tabular}

Sumber: SNI 6389:2011 Konservasi Energi Selubung Bangunan pada Bangunan Gedung

Dari tabel 3 di atas maka penggunaan ACP dengan warna terang cukup baik untuk mengurangi penyerapan panas.

\section{B.3. Analisis Luas Material Transparan}

Luas bukaan jendela pada ruang kantor PPSM Migas Cepu ini lebih dari 30\% luas dinding keseluruhan. Hal ini lebih dari nilai ideal bukaan bangunan yaitu $20 \%$. Hal ini tentunya membuat cahaya yang masuk ke dalam bangunan akan optimal dan membatu penerangan ruang sehingga terjadi kenyamanan visual yang baik

Untuk bukaan bagian atap, terdapat 2 (dua) bagian yaitu bagian tidak transparan dan transparan (skylight). Luas bukaan bagian atap \pm $10 \%$. Ini memang masing belum ideal akan tetapi cukup membuat penerangan alami ke dalam bangunan. Hal lain yang menjadi pertimbangan karena material kaca yang digunakan adalah kaca bening. Jika terlalu luas bukaan bagian atap dikhawatirkan menyebabkan panas yang masuk semakin banyak dan dapat membuat ketidaknyamanan pengguna gedung.

\section{KESIMPULAN}

Berdasarkan hasil analisis faktor eksternal dan internal dihasilkan bahwa:

- Pengukuran suhu udara di ruang transit (lobi, koridor/lorong) rata-rata berkisar antara $26,5^{\circ} \mathrm{C}-33,8^{\circ} \mathrm{C}$. Hal ini memperlihatkan bahwa suhu di lingkungan PPSDM Migas Cepu cukup tinggi.

- Pengukuran suhu di ruang kerja dimana dipengaruhi juga oleh penghawaan buatan yaitu sistem pengkondisian udara yang berkisar antara $24^{\circ} \mathrm{C}-27^{\circ} \mathrm{C}$. Hal ini sudah baik, sesuai dengan persyaratan pada SNI.

- Nilai rata-rata kelembapan udara berkisar antara $43-70 \%$. Hasil analisis ini menunjukkan bahwa kelembapan udara cukup baik untuk beraktifitas.

- Untuk kecepatan angin, ada lokasi yang terdapat gerakan udara. Pengaruh gerakan udara yang merupakan penghawaan alami dapat dirasakan di lantai 1, karena di lantai 1 terdapat 3 (tiga) bukaan alami yaitu lobi utama, lorong kanan dan lorong kiri.

Dari hasil analisis di atas dapat diambil kesimpulan sebagai berikut:

1. Gedung kantor PPSDM Migas Cepu sudah baik dalam mewujudkan konsep yang diaplikasikan dengan pemilihan 
material selubung bangunan, namun terdapat kekurangan pada material kaca yang masih menggunakan kaca bening yang menimbulkan panasnya suhu udara pada ruangan.

2. Ditinjau dari dampak pemilihan material terhadap kenyamanan termal, secara umum sudah cukup baik dalam menunjang kenyamanan termal. Namun terdapat kekurangan pada aspek kecepatan angin, aspek ini dinilai kurang optimal dalam mendukung terwujudnya kenyamanan termal.

\section{DAFTAR PUSTAKA}

Artha Prakoso, Naga, dkk. 2014. Kajian Penerapan Material pada Selubung Bangunan yang Mempengaruhi Kenyamanan Termal dan Visual. Jurnal Reka Karsa, Jurnal Online Institut Teknologi Nasional No. 2, Vol. 2, Agustus 2014. Jurusan Teknik Arsitektur Itenas.

http://archive.epa.gov/greenbuilding/web/html/ about.html, diakses pada tanggal 27 Oktober 2015.

http://info-bedahrumah.blogspot.com/2014/03/ mengenal-jenis-jenis-kaca-dan.html diakses tanggal 13 Desember 2018.

https://www.arsitag.com/article/mengenal-alumunium-composite-panel-acp diakses tanggal 13 Desember 2018.

https://www.homify.co.id/ideabooks/5488334/ aluminium-composite-panel-karakteristik-dan-kelebihannya diakses tanggal 20 Desember 2018.

Lippsmeier, Georg; 1980; Tropenbau Building in the Tropics; Callwey Verlag Munchen

Satwiko. Prastowo, 2008, Fisika Bangunan, Penerbit ANDI, Yogyakarta.

SNI 6389:2011 Konservasi Energi Selubung Bangunan pada Bangunan Gedung.

SNI 6390:2011 Konservasi Energi Sistem Tata Udara Bangunan Gedung.

Undang-Undang No. 28 Tahun 2002 tentang Bangunan Gedung.

UNEP, 2009, Building and Climate Change, UNEP, Paris. 